\title{
Quietness in the Soundscape of the Białowieża National Park
}

\author{
J. Wiciak*, D. Mleczko, A. Ozga, G. Wszolek, J. Wierzbicki, J. Piechowicz, \\ AND P. MAŁECKI \\ AGH University of Science and Technology, Faculty of Mechanic Engineering and Robotics, \\ Department of Mechanics and Vibroacoustics, Al. Mickiewicza 30, 30-059 Krakow, Poland
}

\begin{abstract}
The quietness, defined as the near or complete absence of sound, in the context of the natural environment protection, may be considered a state in which no undesired of foreign sounds occur, and, by analogy to noise, analyzed in two aspects: that pertaining to measurements and the subjective one. The article discusses the lowest levels of sounds recorded at night in the soundscape of the Białowieża Forest. Due to low levels of the examined sounds and the technical problems that occurred while the sounds were being measured and registered, the acoustic examination of the measurement set-up in an anechoic chamber has also been presented. The research is aimed at defining precisely the concept of quietness prevailing in the nature in the subjective aspect by determining both the range of levels and the characteristics of preferred sounds.
\end{abstract}

DOI: $10.12693 /$ APhysPolA.128.A-79

PACS: 43.66.- $\mathrm{x}, 43.66 .+\mathrm{y}$, 87.18.Tt, 87.19.lc, 43.50.Rq

\section{Introduction}

A modern man is surrounded by din and noise most of the time; with the development of industry the environmental noise is continually more perceptible [1]. Taking into account merely the most common source of noise which is the road traffic, analyzing the data included in the acoustic maps and measurements performed by the Chief Inspectorate of the Environmental Protection in the year 2013 [2] in Poland we can state that $66 \%$ of the examined roads are characterized by the level of noise emission above $65 \mathrm{~dB} L_{A e q D}$ in daytime, and on $78 \%$ of roads the noise level exceeds $56 \mathrm{~dB} L_{\text {AeqN }}$ during night time. Additionally, the sonic environment includes also the noise generated by industry [3-5], aircraft, wind turbines [6,7], railways, craft services, farms, playgrounds, municipal facilities, renovations, and household appliances [8]. What is more, the presence of noise from several sources makes segregation of sounds by the ear difficult [9].

The concept of noise [10] is usually associated with loud sounds (in extreme cases, the sounds causing earache or hearing deficiency) or with the sounds hampering execution of tasks connected with one's job [11]. Less frequently, according to the currently adopted definition, this concept includes also burdensome and undesirable sounds causing discomfort. Each kind of environment that generates noise produces a strong effect on the health as well as well-being of a man, and may cause stress, illnesses and in some cases, behavioral changes or disturbances of psychological development [12]. A sudden noise, as a sign of a direct threat, makes our organisms fully alert: adrenaline level increases, muscles become tense, the heart beats faster, and the blood pressure increases - the organism is ready to fight or flee.

*corresponding author; e-mail: jerzy.wiciak@agh.edu.pl
According to the Environment Protection Act [13, 14], in order to protect humans, separate regulations are published determining the accepted levels of the noise produced by transport, industry, aircraft, and power transmission network. The tables show the accepted values of the equivalent sound level $\mathrm{A}$ in $\mathrm{dB}$ depending on the time of the day, object, acoustic category of the area zoning, and exposition time.

Theoretically, at the opposite extreme we should have the absolute quietness understood as absence of sound treated simultaneously as the wave movement in the air (or any other transmission medium) [15] and as a stimulation of the sense of hearing due to perception of this wave. While we can imagine such a situation in the outer space, a question arises whether it is possible to find a spot of absolute quietness on the Earth. This kind of quietness is an environment in which a man could not exist, and this is why the environmental science - dealing with active protection of the environment - defines relative quietness and not the absolute one [1]. At this stage of the study we also have to differentiate between the acoustic concept of measurable quietness from audible quietness, which is a subjective psychological notion. Middle ear is built so that a man can hear the sounds between $20 \mathrm{~Hz}$ and $20000 \mathrm{~Hz}$, so the fact that no sounds are perceived does not mean that there are no acoustic waves propagating in the air. Thus, if there are always some sounds in the air, it is justifiable to ask what is the correlation between the perceptible values and the measurable ones and make an attempt to determine the threshold of quietness not in the audiometric sense as an ability to hear sounds [16], but as a definite, objective description of the state of the acoustic field. In this article the authors deal with the correlation described above and attempt to answer the question:

Can quietness existing in the soundscape of the Biatowieża Forest be defined by a description of acoustic conditions? 
This research question is considered in the context of the acoustic environment of the area where, in good weather in winter, at night, one can hear and record the kind of quietness that exists in the nature only. The anthropology of quietness is a non-definable phenomenon due to individual differences in sensory perception. In the present study, quietness is described as lack of perceptual noise, on the boundary of subjective perception of soundscape, on the borderline between the comfort and the disquiet.

In order to answer the above research question it was necessary, among other things, to check measurement possibilities of the applied spectrum analyzer in the range of low values of sound pressure level.

\section{Acoustic examination of the measuring device in an anechoic chamber}

In laboratory conditions, the most silent place is usually the anechoic chamber. It is a chamber where the conditions of a free sound field are created, insulated as well as possible from the external disturbances both as regards sounds and vibrations. Sound insulation is provided by thick walls lined on the inside with soundproofing panels of appropriate acoustic characteristics, while vibroinsulation is provided by specially selected vibration-proof systems on which the concrete block of the chamber is founded.

TABLE I

Results of measurements of electrical and acoustic noises of the analyzer SVAN 959 for the working mode of a sound measuring set.

\begin{tabular}{l|c}
\hline \hline \multicolumn{1}{c|}{ Frequency weighting } & $\mathrm{dB}(\mathrm{A})$ \\
\hline $\begin{array}{l}\text { Lower limit of the measurement range } \\
\text { (according to the manufacturer's instruction manual) }\end{array}$ & 12.0 \\
\hline $\begin{array}{l}\text { Level of own noise determined by the manufacturer, } \\
\text { with microphone impedance }\end{array}$ & $<12.0$ \\
\hline $\begin{array}{l}\text { Equivalent sound level determined with the use } \\
\text { of microphone impedance }(18 \mathrm{pF} \text { ) }\end{array}$ & 11.5 \\
\hline $\begin{array}{l}\text { Measurement of the chamber background burdened } \\
\text { with the acoustic noise of the measuring equipment }\end{array}$ & 15.3 \\
\hline $\begin{array}{l}\text { A-weighted level of the chamber acoustic background } \\
\text { measured with SVAN 912AE with a } 1^{\prime \prime} \text { microphone }\end{array}$ & 11.6
\end{tabular}

In order to prepare a measuring set to record the changes of pressure, SVANTEK sound analyzer of SVAN 959 type equipped with a $1 / 2^{\prime \prime}$ free field microphone $40 \mathrm{AE}$ by G.R.A.S. and a microphone preamplifier SV12L was subjected to examination in the anechoic chamber. The device has two measurement ranges (LOW and HIGH) and two operating modes (sound meter and sound analyzer). In the instruction manual of the device, the manufacturer declares the measuring range of the values of sound A starting from $12 \mathrm{~dB}$ but does not define the range of measurement of $1 / 3$-octave bands. Due to very low values of acoustic pressure in particular bands of $1 / 3$-octave frequencies, it proved to be necessary to describe the results of the measurements of the acoustic pressure levels with respect to the measurement range of the used wave analyzer. Measurements of electrical and acoustic noise of the device were executed for a typical measuring set configuration (microphone, preamplifier, extension cord, meter) with the compensation filters and calibration corrections appropriate for measurements in the free field [16]. In the examination of the electrical noise of the device, the microphone was replaced by a $18 \mathrm{pF}$ capacitor representing impedance of a microphone, while the acoustic noise was measured in the anechoic chamber. Therefore it should be remembered that it is a measurement of the acoustic background of the anechoic chamber at night time, burdened with the error connected with the acoustic noise of the measuring set values of which cannot be precisely determined. The characteristics of the device's own noises determined for the sound meter function are presented in Table I, while levels of the acoustic pressure for the noises produced by the bond analyzer can be seen in Fig. 1 .

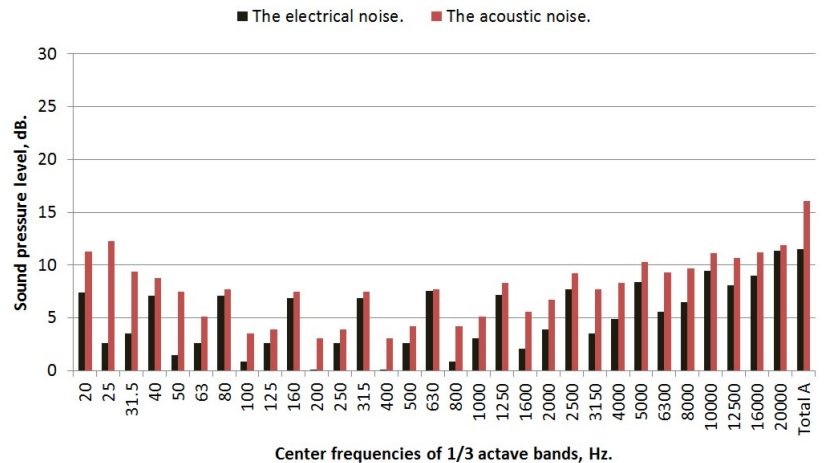

Fig. 1. Spectrum of the sound pressure level of the electrical and acoustic noise of the measuring set-up consisting of a sound analyzer SVAN 959, a microphone G.R.A.S 40AE, and a microphone preamplifier SV12L.

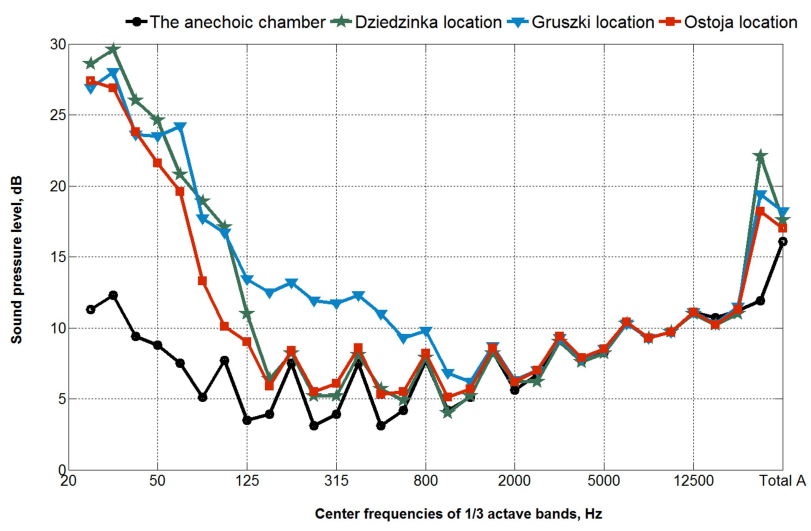

Fig. 2. Comparison of results of spectrum analysis of the acoustic pressure measurements in $1 / 3$-octave bands taken in the Białowieża Forest in quietness and in the anechoic chamber for 15-minute time intervals. Description of measurements in the Białowieża Forest are presented in chapter 3 . 
The measurements were executed due to the difficulties occurring during the attempt to record sounds with low level of acoustic pressure. No measuring sets with sufficiently long difference between the measured sounds and the noise produced by the device were available. Additionally, having no sufficiently reliable specification of the equipment given by the manufacturer, it is impossible to determine or calculate the values showing the ratio of the measured sounds and that of the equipment itself in a given portion of the spectrum (cf. Fig. 2, the range of frequencies above $500 \mathrm{~Hz}$ ).

Analyzing the results of examination of the noises produced by the measuring system working as a sound level meter (measured at the AGH University of Science and Technology and declared by the manufacturer) we can state that the values of the measured sound levels A in the Białowieża Forest presented in the next chapter are above the levels of noise produced by the measuring device. On the other hand, the analysis of the selfgenerated noise produced by the device working as a sound analyzer in 1/3-octave bands shows that in the range of frequencies above $500 \mathrm{~Hz}$, this sound analyzer is not able to measure as low values of acoustic pressure as those occurring in the Forest.

This is confirmed by the spectrum analysis of the measurements taken at three locations within the Forest and in the anechoic chamber. Comparison of the results obtained in 1/3-octave bands is shown in Fig. 2.

For the spectra of middle-frequency bands above $500 \mathrm{~Hz}$, the values of all measurements are equal and they clearly indicate the level of the noises produced by the measuring device in this range.

Relatively higher levels of acoustic pressure in lowfrequency bands $(20-100 \mathrm{~Hz})$ are practically imperceptible in the human reception route due to the characteristics of ear sensitivity (isophonic curves). This is why the signals with spectra shown in Fig. 2 seem to represent "absolute quietness".

\section{Quietness in the soundscape of the Białowieża National Park}

The science that analyzes the man's relations with the environment on the basis of sound, called the acoustic ecology, is also known as ecoacoustics or soundscape ecology $[18,19]$. This meaning of the word ecology does not involve exclusively the sounds coming from the nature; what is analyzed is the soundscape occurring at any chosen place and at any selected time. Searching for a soundscape where quietness reigns is in accord with the definition of the soundscape ecology and is a special case of the acoustic environment of the contemporary man. In order to record the silence reigning in the nature, the authors have carried out their investigations in the area of the Białowieża National Park.

Białowieża Forest has been designated a UNESCO World Heritage Site, a UNESCO Biosphere Reserve, and an EU Natura 2000 Special Area of Conservation. It is

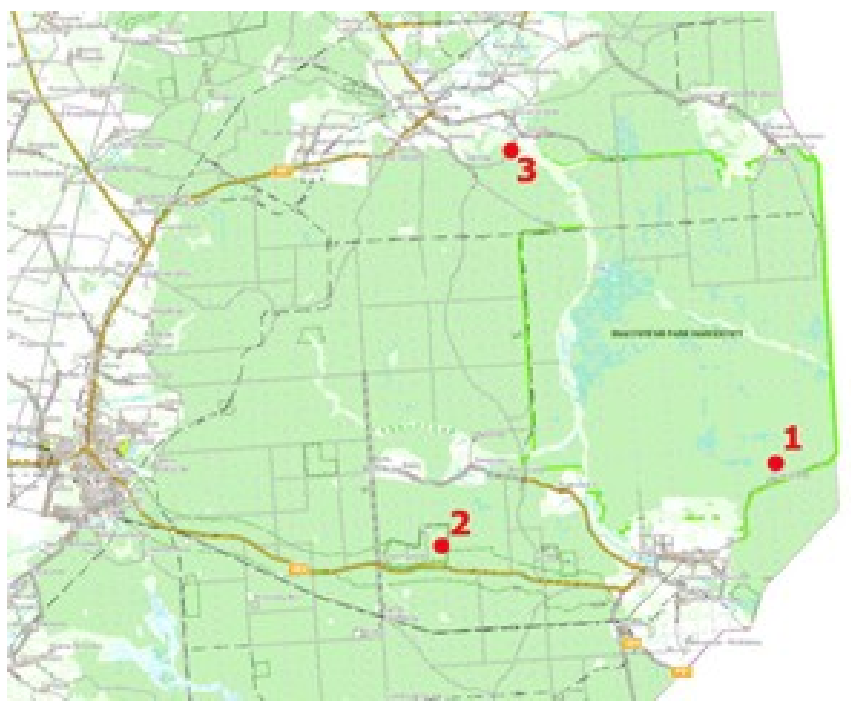

Fig. 3. Distribution of measurement points in the area of the Białowieża Forest.

TABLE II

Meteorological conditions during the period of measurement execution.

\begin{tabular}{c|c|c|c}
\hline $\begin{array}{c}\text { Measurement } \\
\text { location }\end{array}$ & Dziedzinka & Ostoja & Gruszki \\
\hline $\begin{array}{c}\text { GPS } \\
\text { coordinates }\end{array}$ & $\begin{array}{c}\mathrm{N} 52^{\circ} 43^{\prime} 20.79^{\prime \prime} \\
\mathrm{E} 23^{\circ} 25.39^{\prime \prime}\end{array}$ & $\begin{array}{c}\mathrm{N} 52^{\circ} 42^{\prime} 22.10^{\prime \prime} \\
\mathrm{E} 44^{\prime} 47.52^{\prime \prime}\end{array}$ & $\mathrm{N} 52^{\circ} 49^{\prime} 30.28^{\prime \prime}$ \\
\hline $\begin{array}{c}\text { Measurement } \\
\text { time }\end{array}$ & 23.02 .2015 & 24.02 .2015 & 25.02 .2015 \\
\hline $\begin{array}{c}\text { Measurement } \\
\text { date }\end{array}$ & $3: 15-3: 30$ a.m. & $3: 25-3: 40$ a.m. & $3: 40-3: 55$ a.m. \\
\hline $\begin{array}{c}\text { Acoustic } \\
\text { pressure [hPa] }\end{array}$ & 1009 & 1001 & 1014 \\
\hline $\begin{array}{c}\text { Temperature } \\
{\left[{ }^{\circ} \mathrm{C}\right]}\end{array}$ & -2 & 5 & 1 \\
\hline $\begin{array}{c}\text { Humidity } \\
{[\%]}\end{array}$ & 100 & 93 & none \\
\hline $\begin{array}{c}\text { Wind speed } \\
{[\mathrm{m} / \mathrm{s}]}\end{array}$ & $0-1$ & $0-2$ & - \\
\hline $\begin{array}{c}\text { Wind } \\
\text { direction }\end{array}$ & $\mathrm{NE}$ & $\mathrm{SW}$ &
\end{tabular}

the oldest forest in Europe preserved in its virtually natural condition. The studies of quietness were performed at three selected characteristic locations (Fig. 3) at which the level of the acoustic background was registered at favorable weather conditions, presented in Table II:

1. Dziedzinka is a spot most remote from human settlements - it is a location in the strict nature reserve where it is possible to see all indigenous animals and birds subject to strict species protection in Poland.

2. Ostoja is a spot located close to a road. Since it serves as an animal feeding point, it is frequented visited by wisents (European bisons) in the winter. 
3. Gruszki is a location on the border between the natural environment and human settlements. It is a meadow in which one can find several species of animals and birds protected in Poland. At the same time, the closest human dwellings are just $0.5 \mathrm{~km}$ away from it.

The spectra of the sound pressure level in $1 / 3$-octave bands are shown in Figs. 4-6. Measurements were taken for 15-minute time intervals. Very low values of A-weighted sound levels were recorded $(17.6 \mathrm{~dB}, 18.2 \mathrm{~dB}$, and $17.0 \mathrm{~dB}$, respectively). They are the lowest of all levels of sounds recorded throughout the night. Simultaneously, during the same 15-minute period, additional recordings were made with a Soundfield first-order ambisonic microphone ST-350 [20]. This microphone allows to analyze the recorded sounds in the aspect of their spatial distribution, thanks to which we could state that in the signals recorded at each of the microphone locations, no sounds produced by animals, wind, etc. were found. An important reason for it, rarely occurring in other areas, is the absence of noises coming from roads, industrial objects, housing estates, or agricultural activity in the acoustic background.

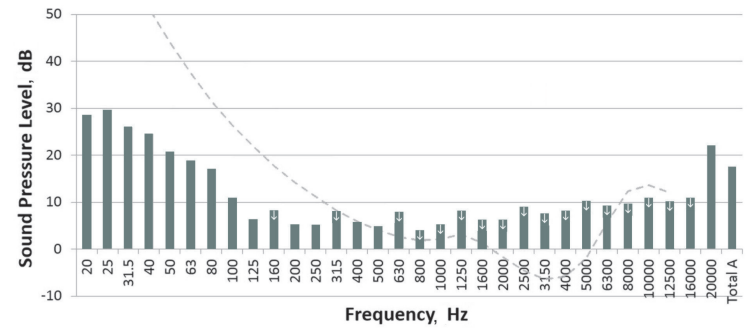

Fig. 4. Spectrum of the sound pressure level in $1 / 3$ octave bands recorded at night at Dziedzinka location.

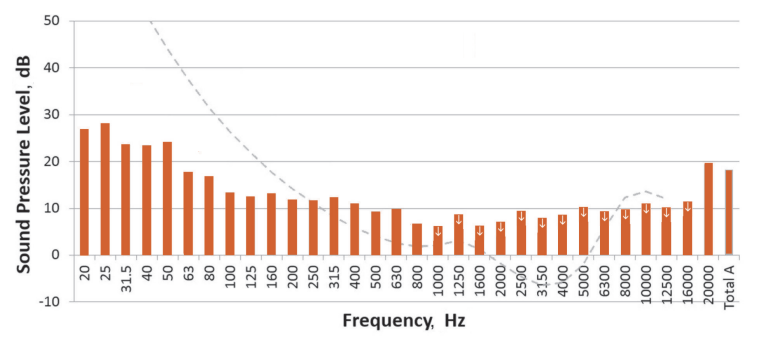

Fig. 5. Spectrum of the sound pressure level in $1 / 3$ octave bands recorded at night at Ostoja location.

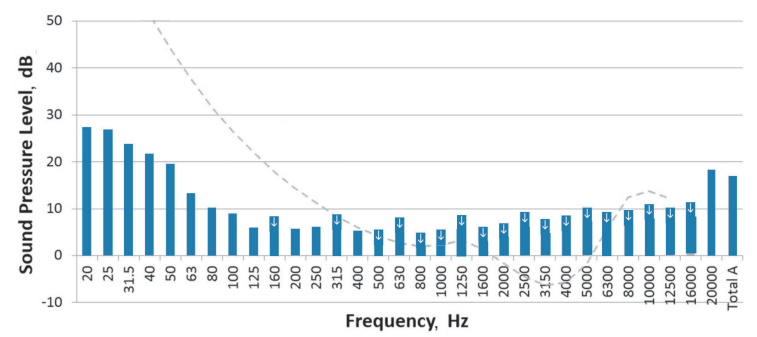

Fig. 6. Spectrum of the sound pressure level in $1 / 3-$ octave bands recorded at night at Gruszki location.
In the diagrams (Figs. 4-6), apart from the measured signal, the Absolute Threshold of Hearing (0-phons according to [21]) was marked as well as the frequency bands in which the values of the signal amplitudes were below the measuring system's own noises (Fig. 1). The absolute threshold of hearing was marked with a dashed line while the bands for which the signal could reach values lower than the recorded ones, due to the limitations of the lower measurement range of the equipment, were marked by arrows on particular bars. The presented results indicate that for locations first (Dziedzinka) and third (Gruszki), the measured values of the levels of sounds within the measuring range of the set-up were below the human threshold of hearing. It was only in the second spot (Ostoja) that in the frequency band 300$800 \mathrm{~Hz}$, the measured values were above the measuring system's own noises. For the bands of medium and high frequencies, to which human ear is most sensitive, the used measuring system is characterized by its own noises far above the threshold of hearing (Fig. 1, Figs. 3-5). The physical value of the acoustic pressure for the indicated range of frequencies is very low but its precise value is unknown. We might guess that it is the values of the acoustic pressure that significantly influence the perception of silence because in the subjective experience of the people taking the measurements, their experience was different in each of the considered locations and highly different from the quietness that is perceive in the laboratory conditions of an anechoic chamber.

Quietness is, on the one hand, a state of mind, and on the other hand it is a measure of quality of the natural environment. Even in a very quiet environment we can hear "silence". This sound has several components visible in the spectrum of frequencies (Figs. 4-6).

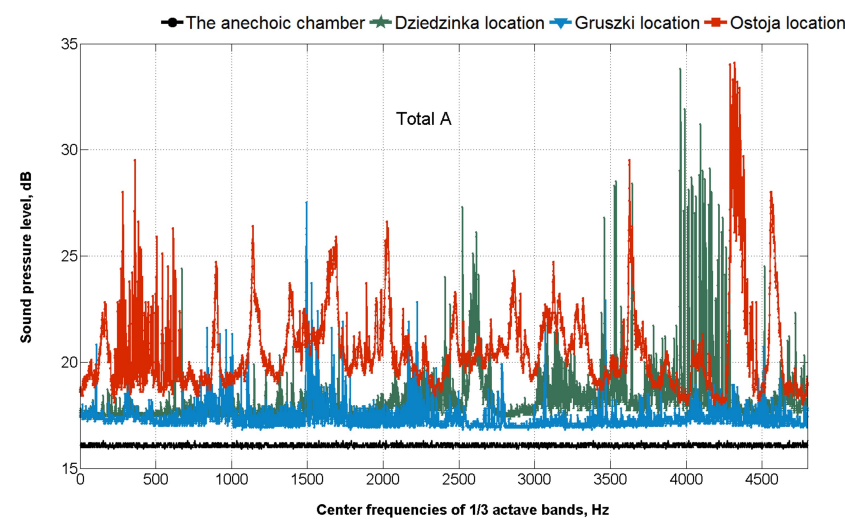

Fig. 7. A-weighted sound pressure level values for selected locations and the anechoic chamber.

In order to avoid limiting the conclusions from the conducted research to a relatively short time interval, additional analyses were conducted of the sound levels in the above-mentioned locations within a much longer sampling period. 80-minute long waveforms were selected, weighted with the A weighting curve as well as with 
the time constant FAST, and averaged every one second. Figure 7 shows time waveforms for 3 measurement spots in the Forest and for an anechoic chamber. The obtained results show that the sound pressure levels were similar, no matter where they were recorded. Higher levels in Ostoja may be caused by a nearby Białowieża-Hajnówka road.

The difference between the minimum A-weighted sound level values for particular measurement spots in the Białowieża Forest and the anechoic chamber is very small. This may be caused by different weather conditions during the measurement sessions. Essential differences between the sound pressure levels can be recognized for the levels higher than the low measurement range. Due to the sterile measuring conditions in the anechoic chamber, oscillations of sound levels are almost absent. For the forest locations, the differences can be noticed in the range $17-35 \mathrm{~dB}(\mathrm{~A})$. In order to quantify the presented variability, histograms were computed and drawn (Fig. 8) for the analyzed time waveforms.

Due to technological limitations at the low measuring range of the equipment, interpretation of the presented histograms is ambiguous. The most extreme bar of the histogram of the lowest sound level and the highest rate
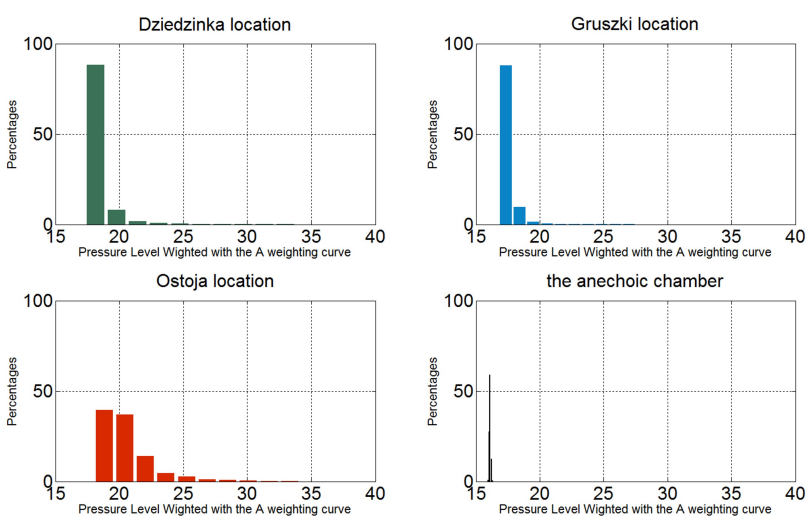

Fig. 8. Histograms of sound levels for particular measuring points in the Białowieża Forest and for the anechoic chamber.

of observation is very similar in its value to the device's own noise. It is only the histogram for the Ostoja location that is characterized by a significant distribution of values in the range of low sound levels. For Dziedzinka and Ostoja spots, the values higher than the own noise level of the measuring system occur very rarely. On the basis of the shape of the distribution curve characterizing measured values shown on the right of the main bar we may conclude that the actual values of the sound pressure at Gruszki and Dziedzinka spots are close to each other, while for Ostoja location they are slightly higher.

\section{Conclusions}

Life in a noise, especially in huge urban agglomerations, has a harmful effect on human health and mental condition. Quietness understood as absence of undesired sounds or sounds in general may be vexing and worrisome or, just the opposite, evoke the feeling of comfort. This aspect of quietness may be considered an important component of the quality of life and is connected with human biological and mental health [11]. This phenomenon must be perceived in two aspects: acoustical and psychological. In quietness, a human being relaxes, takes a rest, calms nerves, and at the same time regenerates the hair cells in the hearing organ, so after coming back to the world hustle, he/she is able to function in this acoustically aggressive environment. Having reached the oldest forest in Europe, the Białowieża National Park, the authors recorded silence generated by the nature in favorable weather at night. Answering the research question concerning quietness present in nature posed above in the Introduction, they recorded the state of acoustic background at the level of $17 \mathrm{~dB}$. In the Białowieża National Park, this silence has also other aspects, psychophysical conditions included - the sense of space, perception of beauty, etc. Considering silence from the psychological point of view we should mention that the response to noise and to the absence of sounds is connected not only with the general nervous sensitivity, age, and habits, but also with the health condition and the level of exhaustion. Therefore, determining the limit value of sound pressure above or below which we can speak of quietness, depends on too many variables connected with perception of an individual person. Additionally, in order to measure such low levels of sound pressure and to analyze the spectra of the measured sounds, it is necessary to have the equipment (sound analyzers) with well-described ranges of the measured sounds and well-defined internal noises for different measuring configurations. These data ought to be declared by manufacturers of the used apparatus.

The measurements taken in the field were analyzed with the help of two methodologies: the spectrum analysis on the basis of 15-minute long observation and with the help of the analysis of statistical distribution for a 80-minute period. The conclusions for the two applied methods are not identical, which indicates the complexity of the problem and the necessity of application of an alternative measuring track with very low own noises.

\section{Acknowledgments}

The project described in this paper has been executed within the project No. 11.11.130.955

The authors wish to express their gratitude to the staff of the Białowieża National Park for their friendly support.

\section{References}

[1] W. Sztumski Man and Environment, University College of Social Sciences, Częstochowa 2012 (in Polish).

[2] Condition of acoustic climate in Poland in 2013, Chief Inspectorate of Environmental Protection, Warszawa 2014 (in Polish). 
[3] D. Pleban, J. Piechowicz, K. Kosała, JOSE 19, 321 (2013).

[4] J.R. Engel, K. Kosała, Arch. Acoust. 32, 251 (2007).

[5] J. Piechowicz, Arch. Acoust. 34, 2 (2009).

[6] C. Kasprzak, E. Skrodzka, J. Wiciak, Acta Phys. Pol. A 125, A-45 (2014).

[7] T. Wszołek, M. Kłaczyński, D. Mleczko, A. Ozga, Acta Phys. Pol. A 125, A-38 (2014).

[8] W. Batko, P. Pawlik, Arch. Acoust. 37, 57 (2012).

[9] P. Kleczkowski, Arch. Acoust. 37, 355 (2012).

[10] Z. Engel, J. Piechowicz, L. Stryczniewicz: Fundamentals of industrial vibroacoustics, AGH, Kraków 2003 (in Polish).

[11] PN-N-01307:1994, Noise. Acceptable values of noise at the workplace.

[12] T. Olearczyk, Quietness in Theory and Practice, Krakowskie Towarzystwo Edukacyjne, Kraków 2014 (in Polish).

[13] Act of 27 April 2007 'Environment Protection Law' (J. Laws 2001, No. 62, Item 627, as amended). Official Journal of Law 2013 item 1232 of October 23, 2013, as amended.
[14] Regulation of the Minister of Environment of October 152013 on publication of consolidated text of the directive the Minister of Environment on acceptable levels of noise in the environment (J. Laws 2014, item 112).

[15] PN-IEC 50(801):1998 International Electrotechnical Vocabulary, Ch. 801: Acoustics and electroacoustics.

[16] P. Kleczkowski, Perception of Sound, Wydawnictwa AGH, Kraków 2013 (in Polish).

[17] G. Wszołek Acta Phys. Pol. A 119, 1081 (2011).

[18] K. Wrightson, Soundscape: J. Acoust. Ecol. 1, 10 (2000).

[19] R. Murray Shafer, The Soundscape: Our Sonic Enviroment and the Tuning of the World, Warszawa 1993.

[20] P. Małecki, J. Wiciak, J. Wierzbicki, Acta Phys. Pol. A 123, 1114 (2013).

[21] ISO 226, Acoustics - Normal equal-loudness-level contour, 2003. 